\title{
Exploring the Interpersonal Meaning in two extracts from Chimamanda Ngozi Adichie's Purple Hibiscus and Chinua Achebe's Anthills of the Savannah : A Comparative Systemic Functional Linguistic Perspective
}

\author{
Dr. Daniel T. Yokossi
}

Doi: 10.2478/jesr-2018-0007

\begin{abstract}
This paper examines Mood Patterns in some passages from Adichie's Purple Hibiscus and Achebe's Anthills of the Savannah. More specifically, two extracts from the above mentioned prose fiction have been purposefully selected, described and analyzed from the Systemic Functional Linguistics perspective in order to reveal how the lexicogrammatical features of the interpersonal meaning of the studied extracts underpin the perception of the two authors throughout their novels. The article goes further and highlights the similarities and differences in the interpersonal functions of the extracts under scrutiny in terms of their contents and how the English language has been used therein to construe the above pinpointed authors' world views of the issues dealt with in their writings. The findings of the study have, among others, revealed that the gap between Achebe's and Adichie's writings is not full size and that the former has actually paved the way to the latter.
\end{abstract}

Keywords: Interpersonal Meaning, Systemic Functional Linguistics, Mood Patterns, Mood types, Modality, Adjuncts

\section{Introduction}

Being the key means whereby people talk to and or exchange goods and services among one another, language has three major functions namely the ideational function, the interpersonal function and the textual function which enables the other two functions to operate (Halliday, 1975). As a matter of fact, rather than scrutinizing the three language functions altogether, the ongoing study focuses on just one of them viz. the interpersonal function through texts analyses. Actually what is meant by interpersonal function? The interpersonal function/meaning of language expresses the interactional meaning that is to say, what the clause is doing, as a verbal exchange between speaker/writer and audience/reader. Indeed, the interpersonal meaning is expressed by the intonation contour; by the 'Mood' block, which may be repeated as a tag at the end; and by expressions of modality which may recur throughout the clause (Halliday \& Matthiessen, 2004, p.328). More clearly, the interpersonal meaning/function establishes a relationship between the speaker and the listener or between the writer and his/her readers and brings to light the writer's hidden message via his/her artistic selection of mood, modality and adjunct structures.

This article aims at scrutinizing the interpersonal meaning in selected extracts from novels by two Nigerian literature icons viz. Chinua Achebe and Chimamanda Ngozi Adichie. More specifically, one extract from Adichie's Purple Hibiscus and another from Achebe's Anthills of the Savannah have been purposefully chosen and analyzed. Findings from the analysis have been interpreted to dig out their messages conveyed within. To descend to particulars, the study opens with a brief survey of the theoretical background to the scholarship, and then moves on to the analysis proper. The study ultimately culminates in the comparison of both writers' studied works of fiction to witness to what point they are similar while highlighting differences between them. 


\section{Theoretical Background to the Study}

\subsection{A Brief Survey of the Grammar of Interpersonal Meaning}

The Interpersonal Metafunction accounts for a different set of meanings which focus on speakers' and listeners' interactions with each other and with the material being conveyed in terms of attitudes and stances expressed in the discourse. The realizations of these meanings occur in terms of mood choices: statement, question, command; and modality realized by modal operators (Eggins, 2004: 172) such as 'might', 'could', 'and should'. They are also realized by adjuncts like 'probably', 'usually' or different sentence adjuncts which relate to the whole of the sentence; examples include 'frankly', 'unfortunately'. From a Hallidayan perspective, the grammar of interaction is viewed as a semantic perspective. Drawing on his point of view, one of the things we are doing, at whatever time we use language to interact, is to establish a relationship between us that is to say, between the person speaking now and the person who will probably speak next (Halliday, 1984, 1985a: 68 - 71, cited in Eggins, 1994, p.149). Indeed, to achieve this vital role of language, Eggins (1994), contends that "we take turns at speaking, we take on different speech roles in the exchange" (p.149). In a nutshell, the interpersonal function relates to all uses of language to express social or personal relations (Halliday, 1971). It is expressed through mood and modality choices. Actually, the Mood structure of the clause refers to "the organization of a set of functional constituents including the constituent Subject" (Eggins, 1994, p.152). Mood analysis then entails a plain understanding of these functional constituents of a clause.

\subsection{Mood Constituents}

Eggins (1994) broadly identified three elements to the MOOD constituents namely: the expression of polarity: either YES (positive polarity) or NO (negative polarity); the nominal-type element which she terms SUBJECT; and the verbal-type element which she calls FINITE (p.156). Indeed, of the three aforementioned constituents, only two viz. the SUBJECT( always expressed by a nominal group) and the Finite( always expressed by a verbal group) are essential to the MOOD given that the polarity constituent can be ellipsed without jeopardizing the argument (p.156). It is vitally important to highlight that the capitalization of the MOOD constituent as advocated by Eggins (1994) is meant to differentiate the MOOD constituent of the clause from the general term Mood which describes the overall structure of the clause (p.156).

\subsection{Mood and Modality Types}

\subsubsection{Mood Types and Speech Functions}

In the process of the interactional relationship to be established while using language, interactants take on different speech roles like giving and demanding, and make such moves as statement, question, offer and command which Halliday (1985) names speech functions. This state of affairs, leads to different mood types. Indeed, each mood type is related to a specific speech function though it (a mood type) can be outstandingly used to express a different speech function from its usual one at times. The following is a recap table of the mood types and their respective speech functions.

Table1: Mood types and their speech functions (extracted from Halliday, 1985; Eggins, 1994).

\begin{tabular}{|l|l|}
\hline Mood Types & Speech Functions \\
\hline -declarative mood & -giving information by stating what is or happens \\
\hline -interrogative mood & -request of information \\
\hline -modulated interrogative mood & -indirect/tempered request of information \\
\hline -imperative mood & -getting somebody to do something \\
\hline -modulated imperative mood & $\begin{array}{l}\text {-getting indirectly/ in a tempered way somebody to do } \\
\text { something by using, say, polite modals. }\end{array}$ \\
\hline -exclamative mood & -expressing wonder, surprise, bewilderment \\
\hline
\end{tabular}




\subsubsection{Modality Types}

Complex area of English grammar, modality is concerned with the different ways in which a language user can intrude on his/her message expressing attitudes and judgements of different kinds. According to Halliday (1985a, p.335), "modality is the area of meaning that lies between yes and no -the intermediate ground between positive and negative polarity." In other respects, Fowler (1986) stated the following about modality:

Modality is the grammar of explicit comment, the means by which people express their degree of commitment to the truth of the propositions they utter, and their views on the desirability or otherwise, of the states of affairs referred to (p. 132)

As it can be grasped from the above definitions, the grammar of modality includes two essential components namely modalization and modulation. According to Eggins (1994, p.180), modalization is the speaker's expression of judgment about the certainty, likelihood, or frequency of something happening or being. It operates either implicitly or explicitly through such Mood Adjuncts as: I'm sure, I think, it is possible, it is certain, it is probable...etc. Indeed, modalization embraces the expression of two kinds of meanings viz. probability and usuality through the choice of a finite modal operator like may, might, could can etc; or further, through the use of Mood Adjuncts of probability, certainty such as possibly, maybe, perhaps, probably, and eventually through both altogether. As for modulation which is the second dimension of modality complementing the former, it is the expression of degrees of obligation and inclination through such finite modal operators as must, should, have to etc, or by an expansion of the Predicator via a passive verb or an adjective (Halliday,1985a, p. 86).

\section{Mood Analysis of the Extracts: Findings and Interpretation}

The analysis of the selected extracts is carried out in the appendix. This sub-section focuses on its findings while highlighting their implications for the better understanding of the studied excerpts on the one hand, and to some extent, to the supplementary understanding of the novels they are extracted from on the other.

All the Mood categories, excluding the modulated interrogative Mood type, have been recorded in the first excerpt from Achebe's Anthills of the Savannah after analysis. The following statistical table tabulates the distribution of the various Mood types embedded in it.

Table 2: Mood -Types distribution in the first extract, (appendix: 19-24).

\begin{tabular}{|l|l|c|c|}
\hline Mood types & Number & Percentage \\
\hline \multirow{3}{*}{ Declarative } & Full declarative & 133 & $83.12 \%$ \\
\cline { 2 - 4 } & Elliptical declarative & 02 & $01.25 \%$ \\
\hline \multirow{4}{*}{ Interrogative } & Full polar interrogative & 06 & $03.75 \%$ \\
\cline { 2 - 4 } & Elliptical Polar interrogative & 02 & $01.25 \%$ \\
\cline { 2 - 4 } & Full wh-interrogative & 08 & $05 \%$ \\
\cline { 2 - 4 } & Elliptical Wh-interrogative & 00 & $00 \%$ \\
\hline \multicolumn{2}{|l|}{ Modulated interrogative } & 00 & $00 \%$ \\
\hline \multicolumn{2}{|l|}{ Imperative } & 09 & $05.62 \%$ \\
\hline \multicolumn{2}{|l|}{ Total ranking clauses \& percentage. } & 160 & $100 \%$ \\
\hline
\end{tabular}

A look at the above statistical table shows that the declarative Mood type especially the full declarative moods sub-class of this category, override the other Mood types. More specifically, the full declarative mood structures form a total of one hundred and thirty-three (133) representing $83.12 \%$ of the overall Mood types identified in the extract. This in fact, is indicative that this excerpt is an informative one. Furthermore, this recurring linguistic feature in the analyzed text is evocative of Achebe's consistency in writing. Two elliptical declaratives have been recorded representing $01.25 \%$. Indeed, Achebe has used this linguistic feature to provide a feedback to his readers. Moreover, it also highlights the dialogic mode of the excerpt. 
The interrogative Mood type has also been recorded as mentioned earlier. But the full whinterrogative sub-class dominates this Mood category, followed by the full polar interrogatives. To go into details, the full wh-interrogatives are ten (10) in number as indicated in clauses $12,22,48$, $50,51,52,60,97,114$, and 115; whereas the full-polar interrogatives are six (06) in number witnessed in clauses $24,25,59,61,70$, and 137 . While four elliptical polar interrogatives have been recorded, in clauses 108,116, 128 and 150, no elliptical wh-interrogative has been identified. A look into these interrogative mood structures reveals that Major Sam has used most of them as witnessed in clauses $24,25,50,51,52,53,60,61,70,114,115,116,128$, and 137; fourteen on aggregate. This actually highlights the authority and power that this participant embodies as the new head of the state of Kangan. The reader witnesses this power influence he is endowed with over the other participants he is in relationship with in some of the interrogative moods as those in clauses $70,114,115$, and 137 . Indeed, Achebe has certainly used this linguistic construct to show how treacherous, callous, disgusting and wicked the politicians of this era in Nigeria were. The modulated full polar interrogative used by Chris in clause 59 highlights the crushing power inequality existing between him and Major Sam; and by extension between the politicians of this period and their nations in Nigeria in particular and Africa on the whole.

The imperative moods on the other hand are eleven in total and can be witnessed in clauses 20, 27, 68, 69, 84, 117, 138, 139, 140, 156, and 160. Major Sam all alone attains ten imperative mood structures while Chris who he is talking with in the text achieves only one as it can be witnessed in clause 20. This linguistic construct as said earlier is symptomatic of the crushing authority Major Sam is endowed with. It is further depictive of the anarchy, autocracy, authoritarianism, dictatorship, and victimization Nigerians were suffering from their political leaders. Additional illustration of Major Sam's crushing authority is displayed to the reader via his use of the imperative moods in clauses 138, 139, and 140 in particular. Achebe has used the above pinpointed imperative moods to show how selfish politicians are. They manage to fight just for their own interests no matter what it costs others (the people they lead). In addition Achebe has skillfully used some of the imperatives to show that these politicians only care for or show kindness to their people and peers when their interests are at stake as illustrated in clause160. In other respects, Chris's use of the imperative mood in clause 20 with the vocative adjunct occurring with it is symbolic of his politeness towards the authoritarian Major Sam. The selection in modality will certainly complete the meanings being conveyed through these Mood types.

All the two types of modality viz. modalization and modulation have been identified in this excerpt. Their statistical table is presented as follows:

Table 3: Statistical table of Modality in the first Excerpt, (appendix: 19-24).

\begin{tabular}{|c|c|c|c|}
\cline { 3 - 4 } \multicolumn{2}{c|}{} & Number & Percentage \\
\hline \multirow{2}{*}{ Modality types } & Modalization & 19 & $67.85 \%$ \\
\cline { 2 - 4 } & Modulation & 09 & $32.14 \%$ \\
\hline Ranking clauses & \& percentage & 28 & $100 \%$ \\
\hline
\end{tabular}

As indicated in the above statistical table, the modalized structures are nineteen (19) on aggregate representing $67.85 \%$ of the overall modality type recorded in the excerpt while the modulated structures are just nine (09) in number. Both modalization and modulation are realized through finite modal operators and a modulated predicator as indicated in clause 153 of the analysis carried out in the appendices.

As a matter of fact, this higher use of modalization over modulation highlights the way the author i.e. Chinua Achebe creates a less authoritative, more suggestive tenor; balancing, by this means, the power inequality inherent in the modulation.

As for the adjuncts, they have all been recorded aside from the polarity adjunct type. The following table tabulates the distribution of the different types of adjuncts embedded in the excerpt. 
Table 4: Distribution of Adjuncts in the first excerpt, (appendix: 19-24)

\begin{tabular}{|l|l|c|c|}
\cline { 2 - 3 } \multicolumn{1}{c|}{} & Number & percentage \\
\hline \multirow{4}{*}{$\begin{array}{l}\text { Types of } \\
\text { Adjuncts }\end{array}$} & Circumstantial & 86 & $55.48 \%$ \\
\cline { 2 - 4 } & Mood & 07 & $04.51 \%$ \\
\cline { 2 - 4 } & Polarity & 00 & $00 \%$ \\
\cline { 2 - 4 } & Comment & 03 & $01.93 \%$ \\
\cline { 2 - 4 } & Vocative & 03 & $01.93 \%$ \\
\cline { 2 - 4 } & Conjunctive & 47 & $30.32 \%$ \\
\cline { 2 - 4 } & Continuity & 09 & $05.80 \%$ \\
\hline \multicolumn{2}{|l|}{ Total Adjuncts \& percentage } & 155 & $100 \%$ \\
\hline
\end{tabular}

As it can be seen from the above statistical table, the circumstantial adjuncts dominate the other adjunct types with a total number of eighty-six (86) circumstantial adjuncts representing $55.48 \%$ of the overall recorded adjuncts. Indeed, Achebe has used this crushing number of circumstantial adjuncts to increase the experiential contents of the excerpt.

Conjunctive adjuncts rank second in this excerpt and are forty-seven representing $30.32 \%$. This high proportion of conjunctive adjuncts in the excerpt is indicative that Achebe has rhetorically organized the information in this excerpt so that it can be easily understood by his readers.

The continuity adjuncts rank third and are nine (09) on the whole. This considerable number of continuity adjuncts has been used to highlight the face to face talk or argument that Chris and Major Sam had as regards the suspension letter Sam wanted Chris to write and hand over to Ikem. In fact Achebe has further used these continuity adjuncts to contribute to the rhetorical organization of his message in the excerpt.

As for the Mood adjuncts they are also not negligible. In fact they constitute a total number of seven (07). The proportion of these adjuncts in the excerpt shows that Achebe has used grammar to temper his message.

Both the comment and vocative adjuncts occur in the excerpt at equal rate. To descend to particulars, they count each three, representing $01.93 \%$ per category. While the comment adjuncts have been used to assess Chris's and Sam's judgments on the one hand, the vocative adjuncts have been used to highlight the power inequality between Chris and Major Sam. In fact, vocative use has been non-reciprocal between these pinpointed participants. As illustration, whereas Chris uses the title "Your Excellency" to address Major Sam as witnessed in clauses 20 and 110, the latter Addresses Chris using his first name "Chris" or the personal subject pronoun "you" as highlighted in clauses 150 and 140 to name these ones only. At this point in time, I am going to switch to the second extract from Adichie's Purple Hibiscus. Here is what the distribution of Mood patterns looks like in this second excerpt:

Table 5: Mood -Types distribution in the second excerpt, (appendix: 19-24).

\begin{tabular}{|l|l|c|c|}
\hline \multicolumn{2}{|l|}{ Mood types } & Number & Percentage \\
\hline \multirow{3}{*}{ Declarative } & Full declarative & 94 & $83.18 \%$ \\
\cline { 2 - 4 } & Elliptical declarative & 05 & $4.42 \%$ \\
\hline \multirow{4}{*}{ Interrogative } & Full polar interrogative & 04 & $3.53 \%$ \\
\cline { 2 - 4 } & Elliptical Polar interrogative & 03 & $2.65 \%$ \\
\cline { 2 - 4 } & Full wh-interrogative & 04 & $3.53 \%$ \\
\cline { 2 - 4 } & Elliptical Wh-interrogative & 00 & $00 \%$ \\
\hline \multicolumn{2}{|l|}{ Modulated interrogative } & 00 & $00 \%$ \\
\hline \multicolumn{2}{|l|}{ Imperative } & 03 & $2.65 \%$ \\
\hline \multicolumn{2}{|l|}{ Total ranking clauses \& percentage } & 113 & $100 \%$ \\
\hline
\end{tabular}

A look at the above statistical table reveals that all the four Mood types have been made use of in the text. The predominance of the full declarative Mood types here is symbolic of information exchange between the author and her targeted audience. In fact, Adichie, as witnessed in the extract from her Purple Hibiscus, is knowledgeable of a number of political, religious and social disasters undermining her country and therefore would like to share and submit them to her readers' analyses, for a collective awareness in order to find reliable and sustainable solutions with 
a view to systematically eradicating or improving them. Actually, this linguistic choice made by Chimamanda N. Adichie, a contemporary novelist, shares a lot in common, as observed in the first extract, with that of Chinua Achebe. The few elliptical declaratives identified show that the interactants in the passage are sometimes involved in some informal situations. A close look into the interrogative mood structures, whatever they are, shows that the power continuum among the participants is unequal, the contact infrequent and the affective involvement very low as exemplified in clauses $20,28,47,59,71,86,93$ of the analysis carried out in the appendix. In other respects, the use of the imperative Mood structure to the detriment of the modulated interrogative Mood structure is similarly symptomatic of an interactive situation wherein participants are involved in unequal power relations. The selections in modality will certainly add to these tenor dimensions, won't they?

The selection in modality throughout the current excerpt is presented in the statistical table hereafter:

Table 6: Modality statistical table in the second excerpt, (appendix: 19-24).

\begin{tabular}{|c|c|c|c|}
\cline { 3 - 4 } \multicolumn{2}{c|}{} & Number & Percentage \\
\hline \multirow{2}{*}{ Modality types } & Modalization & 04 & $44.44 \%$ \\
\cline { 2 - 4 } & Modulation & 05 & $55.55 \%$ \\
\hline Ranking clauses & \& percentage & 09 & $100 \%$ \\
\hline
\end{tabular}

As it can be noticed, the selection in modulation, which stands for the expression of obligation and necessity, prevails over the selection in modalization expression of probability or usuality. This modality feature in the excerpt is highly symptomatic of the striking unequal power reigning among the participants in interaction. In fact, the role relationship is one in which some interactants, owing to the power inequality, give strict order to others. A vivid example is that witnessed between Papa Nnukwu and Father Amadi in clause 66 of this excerpt available in the appendices. As it can be witnessed, the power continuum is one which depicts subordination. One would think that it were a father speaking to his son. In fact, Chimamanda N. Adichie has purposefully devised such a role relationship among her characters to create a framework that enables her to impose what she thinks are the social and moral values to be developed or encouraged in her falling society. Actually, as a priest, Father Amadi knows quite well that one of the key Christian life principles is that one should always endeavor to tell the truth, the whole truth and nothing but the truth since he had sworn an oath for that before he started ministering. But unfortunately, Father Amadi contends that it will be hard not to tell lies to the ignorant souls as stated in clause 74. This is actually descriptive of a crumbling society in which values are not only upside down, but are also more and more degrading and depraving. Adichie, via the tenor variable of modulation viz. the expression of both obligation and necessity, is conveying the message that it is high time her contemporaries changed ways and manners for better and valuable societies to live in. Conversely, the use of modalization, which is but the expression of Adichie's attitude towards what she's saying, is symptomatic that she is not quite sure that her stance will be welcomed by her addressees i.e. her audience considering how much deep rooted and engrained the evil practices being castigated here are already in the societies Adichie intends to save from jeopardy. Given that adjuncts are clause elements that contribute some additional information, I am going to take a look at them and see to what extent they balance the information provided by the modality selection in the excerpt under scrutiny. The distribution of adjuncts in the excerpt is as follows:

Table 7: Distribution of Adjuncts in the second excerpt, (appendix: 19-24).

\begin{tabular}{|l|l|c|c|}
\cline { 2 - 3 } \multicolumn{1}{c|}{} & Number & percentage \\
\hline \multirow{4}{*}{$\begin{array}{c}\text { Types of } \\
\text { Adjuncts }\end{array}$} & Circumstantial & 50 & $48.54 \%$ \\
\cline { 2 - 4 } & Mood & 08 & $7.76 \%$ \\
\cline { 2 - 4 } & Polarity & 01 & $0.97 \%$ \\
\cline { 2 - 4 } & Comment & 01 & $0.97 \%$ \\
\cline { 2 - 4 } & Vocative & 08 & $7.76 \%$ \\
\cline { 2 - 4 } & Conjunctive & 32 & $31.06 \%$ \\
\cline { 2 - 4 } & Continuity & 03 & $2.91 \%$ \\
\hline \multicolumn{2}{|l|}{ Total Adjuncts \& percentage } & 103 & $100 \%$ \\
\hline
\end{tabular}


A quick look at the above statistical table reveals that all the adjuncts types have been identified in the excerpt. Indeed, the circumstantial adjuncts are extensively prevailing over the other types with a total percentage of $48.54 \%$. This, on the whole, means that this text has been written to give information. The textual conjunctive adjuncts rank second. They are thirty-two (32) on the whole throughout the excerpt and represent $31.06 \%$ of the total number of adjuncts identified in the excerpt. They are certainly meant to add textual meaning to the mood patterns of the excerpt and, beyond this, to the whole novel it has been extracted from. Their considerable number in the excerpt implies that Chimamanda N. Adichie has rhetorically organised the passage. The rhetorical organization in question is that whereby conjunctive elements are used to provide linking relations between clauses that relate to one another. In fact, these conjunctive elements express the logical meanings of elaboration extension and enhancement as elaborated on in Eggins(1994:169). As illustration, there is for instance an elaboration relationship viz. a relationship of statement or clarification whereby one sentence is a restatement or representation of a previous one between clauses 63 and 64: [63. "We go to the white man's land and the black man's land, sir, 64. Any place that needs a priest]. In other respects, there is also an extension relationship i.e. a relationship of either addition or variation between clauses 95 and 96 ["That streak of madness has returned and is disturbing you again, okwia?"]

Besides, there is an enhancement relationship, that whereby one sentence can extend on the meanings of another in terms of such dimensions as time, comparison, cause concession or condition as illustrated in clauses: 109, 110 and 110 of the analysis carried out in the appendix. All these logical meanings of elaboration, extension and enhancement provided by the conjunctive adjuncts added to the continuity textual adjuncts identified in the excerpt, provide both cohesive and coherent ties for the internal organization of the text and allow its readers to get its gist quite more easily and effectively.

Mood adjuncts rank third with a percentage of $7.76 \%$. The Mood adjuncts identified here in this excerpt are those expressing both probability and intensification as illustrated in clauses 46,55 , 85 , and 92 of the analysis carried out in the appendix. The presence of the Mood adjuncts expressing intensification is very significant. In fact, Adichie has certainly used them to intensify or to lay emphasis on the message being conveyed through her writing. Those expressing probability are revelatory of her uncertainty about the sustainable positive change she expects via her writing since this does not depend on her alone but also on her society targeted members to whom she has written her piece of literary achievement.

Mood adjuncts expressing presumption and usuality are systematically missing in this excerpt. This actually suggests that there is no presumption as for what Adichie writes about. Indeed her writing depicts real social facts undermining her contemporaries. So behind her fiction hide a lot of real life crumbling situations she would like her contemporaries to recover from. Further, the nonappearance of the usuality mood adjuncts is as well symptomatic of the fact that social realities are never static and that societies keep changing because of human beings' dynamism. This again is suggestive that changes can still be operated for better living conditions if the writer's contemporaries are really willing.

Both, the polarity and the comment adjuncts are barely used in the excerpt. They constitute each $0.97 \%$ of the overall identified Mood adjuncts. The polarity adjunct used here realizes an interpersonal meaning establishing a role relationship between Amaka and Father Amadi functioning as an elliptical constituent (45): "no".

As for the vocative modal adjuncts, they rank third just as the Mood adjuncts with the same number (08) representing $7.76 \%$. Their use in the excerpt, relates dimensions of power, contact and affect. A careful look into the vocative adjuncts of this excerpt clearly reveals that their use is non-reciprocal highlighting the unequal power interaction among the participants involved in the dialog. For example, when Amaka addresses herself to Father Amadi, she always adds the Vocative "Father", but he, in turn, doesn't do so. He rather answers back without using any vocative. This in fact highlights the inequality existing in the power continuum that binds them together. Moreover, no nickname has been used in connection with the vocative adjuncts as used in this excerpt. This shows that contact among the participants involved in the text viz. Aunty Ifeoma, Papa Nnukwu, Kambili and Amaka is not at all frequent, but rather infrequent. In addition, 
the affective involvement among these participants is low. As a matter of fact, they use formal given names to address themselves to one another throughout their conversations.

\section{Comparison}

As careful readers of this paper might have noticed from the foregoing discussion, the two studied texts share a lot in common. For instance, the declarative mood type is noticeably the most overriding one in the two analyzed extracts. While they count one hundred and thirty-three (133) out of the hundred and sixty(160) recorded mood types in the first extract, they add up to ninety-nine (99) out of the one hundred and thirteen (113) mood types recorded in the second extract. In the same vein, the interrogative mood type also dominates the modulated and imperative mood type categories in the studied excerpts with an aggregate number of sixteen (16) in the first extract and eleven (11) in the second one.

Another thing that is strikingly common to either of the two analyzed excerpts is that both the circumstantial and conjunctive adjunct types prevalently dominate the other adjunct types. While the circumstantial adjuncts have dominantly and commonly been used by the two authors to boost the experiential density of their texts by expressing some circumstances related to the message being delivered, complementing by this way the strategies used by each of them to make these texts well written in mode, the conjunctive adjuncts have been used on the other hand, to provide a rhetorical organization of their texts, and add textual meaning to their mood patterns by establishing linking relations of elaboration, extension and enhancement. More to the point, they (Conjunctive adjuncts) underline chronology in the texts allowing readers to make connections between foregoing scenarios or episodes and the following ones. Both the coordinators (and, but, then etc) along with the outstanding intensive use of "and", and subordinators (when, as, that etc.) have been identified making the novels well structured, logical, accessible and very captivating. It is further vitally important to highlight as an additional piece of information to what is said earlier about the circumstantial adjuncts that the most prevailing ones all through the analyzed excerpts are the matter, cause, accompaniment, location (of temporal and spatial sub-types), and the manner circumstantials. Indeed, they have been used by both authors to respectively highlight the subject matter they deal with, the various possible causes of the problems they denounce, the follow up measures to ensure sustainable and peaceful living conditions, the place where to enforce all these measures, and the various suggestive ways by the authors to get all this achieved. The meaning of the vocative adjuncts, which have also been recorded in each of the two excerpts, has culminated in terribly analogous conclusions as accounted for by the interpretation carried out in the foregoing subsection. A close look into the other remaining adjunct types shows that the mood, the polarity, and the comment adjunct types have been recorded at an almost approximate number. A glimpse at the statistical tables provided in this article account for this. All this actually highlights the tremendous similitude that is in the writing styles of the two authors in hand.

Conversely, the selection in modality by the two authors is remarkably different. As a matter of fact, while 19 modalized clauses have been recorded in the first extract, only four have been recorded in the second one. Likewise, nine (09) modulated structures have been identified in the first excerpt whereas four (04) have been registered in the second one. This clearly indicates that despite the proximity in the two authors' writing styles as pinpointed above, they have linguistically encoded their conveyed messages differently at times. It further accounts for the literary art devised by each of the studied authors in the process of the delivery of their various messages to their readership. More to the point, knowing that modalization embraces the expression of usuality, the presence of these linguistic features in both Achebe's Anthills of the savannah published in 1987 and in Adichie's Purple Hibiscus published some sixteen years later (2003), shows that the political, religious and social evils castigated in Adichie's studied fiction are not new problems but recurrent ones previously castigated by her forerunner Achebe. This state of affairs then connotes that Nigerian political, social and religious concerns have not improved over those years so much so that Adichie would like to chip in for her female literary contribution to their respective betterment. Eventually, the fact that there has been more selection of modulated structures in Achebe's studied text than in Adichie's one is revelatory of gender influence over fiction writing. As a matter of fact, 
while men can be tolerated for their bossy character in our African societies, women are not unfortunately. As a consequence, the fewer number of the expressions of obligation and necessity by Adichie here is evocative of her desire to give her text a female tone.

\section{Conclusion}

This article has explored the interpersonal meaning in two extracts from Achebe's Anthills of the Savannah and Adichie's Purple Hibiscus with a view to end up comparing both authors' writings. The results of the analysis from the point of view of their linguistic coding are very impressive. As a matter of fact, via their special use of the mood types; their selection of the modality and adjunct types, their cri de Coeur as regards the political, social, and religious evils castigated in their studied texts comes out more clearly as a valuable means to arouse public awareness for the triumphant recovery of their country from the perils it has been undergoing for years now. In fact Nigerians have to stand up as one man to struggle hard to get their country out of the rut for their better living conditions. Instead of selfishly craving for power as witnessed through the character of Major Sam in the first extract, Nigerian political leaders should stop being wicked, unfair and ungrateful to the people who have hoist them into that position of power by playing their leading part for the upholding of a growing democracy for the happiness of the nation they rule. Religious leaders should also work hard for peace maintenance among the different ethnic groups of the country by being upholders of good morals unlike Father Amadi in the second extract. Interreligious dialogue and tolerance should be promoted to avoid another civil war breaking out again after the Biafran Civil war of 1967.

In other respects the comparison carried out has shown that the two studied authors share a lot in common in terms of their God-gifted styles of writing. It has also pinpointed differences between them as regards the way each of them has chosen to get their messages across to their readership. It has further revealed that Adichie has taken over from Achebe in so far as the political, social, and religious issues she has dealt with had been dealt with years before by her forerunner Achebe who paved her the way. To round off, this study has definitely contributed to a very large extent to further understandings of Achebe's Anthills of the Savannah and Adichie's Purple Hibiscus.

\section{References}

Achebe, C. (1987).Anthills of the Savannah. New York: Anchor Press.

Adichie, C. N.(2003). Purple Hibiscus, First Edition. Lagos: Farafina

Brown,K.(2004).Encyclopedia of Language and Linguistics, Second Edition.Volume1, Elsevier: The Pergamon Imprint.

Butt, D., Fahey, R., Feez, S., Spinks, S. and Yallop, C. (2000) Using Functional Grammar: An Explorer's Guide, Sydney, Australia: National Centre for English Language Teaching and Research, Macquarie University.

Crystal, D. \& Davy, D. (1969). Investigating English style. New York: Longman Group Ltd.

Chapman, R. (1973). Linguistics and literary style. New York: Holt, Rinehart and Winston, Inc

Dik, C. S.(1989). The Theory of Functional Grammar. Partl: The Structure of the clause. Dordrecht: Foris Publications.

Eggins, S. (1994). An Introduction to Systemic Functional Linguistics. London: First Edition Printer Publishers.

Eggins, S. (2004). An Introduction to Systemic Functional Linguistics, (2nd ed.). New York \& London: Continuum.

Fowler, R.(1977/1983). Linguistics and the Novel. London and New York: Methuen \& Co. Ltd.

Halliday, M. A. K. ([1978] 1979) Language as a Social Semiotic: The Social Interpretation of Language and Meaning, London: Edward Arnold.

Halliday, M.A.K. (1983). The language of literature: A stylistic introduction to the study of literature. Oxford: Pergamon Press.

Halliday, M. A. K. (1985). An introduction to functional grammar. London: Edward Arnold.

Halliday, M.A.K. and Hasan,R. (1985/1989). Language, Context, and text: Aspects of Language in a socialsemiotic perspective. Oxford: Oxford University Press.

Halliday, M. A. K. and Martin, J. R. (1993). Writing Science: Literacy and Discursive Power. London: The Falmer Press 
Halliday, M.A.K.(1994). An Introduction to Functional Grammar, (2nd ed).London: Hodder Arnold. Halliday, M. A. K. (2002) Linguistic studies of text and discourse. London and New York: Continuum.

Halliday, M. A. K. \& Matthiessen, C. M. I. M. (2004). An Introduction to Functional Grammar (3rd ed.). London: Hodder Arnold.

Matthiessen, C. (1995). Lexico-grammatical cartography: English systems. Tokyo: International Language Science Publishers.

Amoussou, C. Y. (2014). "Discourse tenor, context and character in the lawyer's monster parable (Petals of Blood)", in Particip'Action vol.6, n¹ (pp.147-70) Lomé- Togo.

\section{Appendix}

\section{Mood analysis key:}

$\mathrm{S}=$ Subject, $\mathrm{F}=$ Finite, $\mathrm{Fn}=$ negative, $\mathrm{Fms}=$ modalized, $\mathrm{Fml}=$ modulated $\mathrm{P}=$ predicator, $\mathrm{Pml}=$ modulated Predicator, Pms=modalised Predicator, $\mathrm{F} / \mathrm{P}=$ fused Finite and Predicator. $\mathrm{C}=$ Complement, $\mathrm{Ca}=$ attributive Complement. $A=$ Adjunct, $A c=$ circumstantial, $A m=\operatorname{mood}, \quad A o=$ comment, $A p=$ polarity, $A v=$ vocative, $A j=$ conjunctive, $A t=$ continuity. $W h=w h$ element; $W h / S, W h / C$, WhAc=fused $W h$ element $M n=$ minor clause. MOOD element of ranking (non-embedded) clauses is shown in bold.

\section{Excerpt N¹: From Anthills of the Savannah by Chinua Achinua, Chapter11(Pp131-134)}

1.His EXCELLENCY(S) was $(\mathrm{F})$ pacing $(\mathrm{P})$ agitatedly $(\mathrm{Ac})$ like a caged tiger(Ac) in the confined space between his desk and the far wall(Ac), 2.his hands(S) held(F/P) tensely(Ac) behind him(Ac),// 3.right fist(S) $\operatorname{gripped}(F / P)$ in left palm $(A c)$. 4. He (S) motioned(F/P) Chris $(C)$ to sit $(P) / / 5$.and $(A j)$ continued(F/P) to pace $(P)$ for what $(\mathrm{Wh} / \mathrm{S})$ seemed(F/P) like a full minute more(Ac) 6.before(Aj) he(S) spoke(F/P):

7."At last!(Ao) But(Aj) God(S) knows(F/P)// 8.I(S)did not(Fn) ask(P) for it(Ac). 9.It(S)'s(F) you, my oldest friends $(C)$, //10.you and(Aj) Ikem who(S) swore(F/P) for reasons best known to you(Ac)// 11.to force(P) a show-down $(C)$. 12.What(Wh/C) more can(Fms) I(S) say(P) 13.except(Aj) So(Ac) be(P) it(C)...14.While(Aj) investigations(S) continue(F/P) into lkem's link with the Abazon agitators(C) 15.he(S) cannot(Fnms) continue to $\operatorname{edit}(P)$ the National Gazette $(C)$. 16. But $(A j) \mathbf{I}(\mathbf{S})$ must $(\mathbf{F m l})$ still $(\mathbf{A m}) \operatorname{do}(P)$ things $(C)$ properly and constitutionally no matter the provocation(Ac). 17.That $(\mathbf{S})$ 's $(F)$ why $(W h / A c)$ I $(\mathbf{S})$ have $(F)$ sent $(P)$ for you (Ac).18.I(S) want(F/P) you (C) as Commissioner for Information (Ac)// 19.to issue (P) a formal letter (C)// suspending $(P)$ him $(C)$ with immediate effect $(A c)$."

20."Hold (F/P) it(C), Your Excellency (Av). 21.I(S) don't(Fn) understand $(P)$. 22.What $(W h / C)$ exactly(Am) is (F) he(S) supposed(P) //23.to have(P) done?(P)"

24. "Are $(F)$ you $(S)$ serious $(\mathrm{Ca})$ ? 25.You(S) really $(\mathrm{Am})$ don't $(\mathrm{F})$ know? $(\mathrm{P})$ ",

26.'I (S) am (F) afraid no (Ca)"

27.'Well(At), let's(S) not waste (Fn/P) time(C) 28.by getting into $(P) / / 29 . w h o(W h / S)$ knows(F/P) what $(C)$, now...(Ac) 30.Intelligence reports(S) have(F) established(P)// 31.that $(A j)$ he(S) was $(F)$ involved(P)//32.in planning $(P)$ the recent march $(C)$ on this $P$ alace $(A c)$ by agitators $(A c) / /$ 33.claiming $(F)$ to come $(P)$ from Abazon $(A c)$. 34.In fact $(A j)$ they $(S)$ were $(F)$ found $(P)$ on careful investigation $(A c) / / 35$. to be $(P)$ mostly $(A c)$ motor-park touts, drug pushers and other criminal elements (Ca) right here in Bassa.(Ac)"

36.'I(S) am(F) sorry(Ca) 37.but(Aj) I(S) can't(Fnms) believe(P) that. (C)"

38."In this job(Ac) Chris, beliefs(S) are not(Fn) my primary concern(C). 39.I(S) am(F) no bishop(P). 40.My concern $(S)$ is $(F)$ the security of this state(C). 41.You(S) should(Fml) know $(P)$ that $(A j) ; 42 . y o u(S)$ are $(F)$ Commissioner for Information(C). 43.Anyhow(Aj), let me(S) assure(F/P) 44.there(S) is(F) incontrovertible evidence $(\mathrm{Ca}) / /$ 45.that $(\mathrm{Aj}) \operatorname{lkem}(\mathrm{S})$ was $(\mathrm{F})$ in contact $(\mathbf{A c})$ with these fellows $(\mathbf{C})$ in the quadrangle right here $(\mathrm{Ac}) / / 46$.and $(\mathrm{Aj})$ later(Ac) drove $(\mathrm{P})$ to a hotel in North Bassa(Ac)//47. to hold(Pm16) a secret meeting $(\mathbf{G})$ with them(Ca). 48. How (Wh/Ac)'s(F) that(S)? 49.Well(At), you(S) seem(F) to be(P) in a skeptical $\operatorname{mood}(A c)$; 50.what $(\mathrm{Wh} / \mathrm{C})$ will(Fms) you(S) say $(\mathrm{P})$ then $(\mathrm{Ac})$ 51.if(Aj) I(S) tell(F/P) you(C) //52.that $(\mathrm{Aj})$ the security agents (S)shadowing $(F / P)$ him $(C)$ actually $(A m)$ arrested $(P)$ him(C) for a minor traffic offence $(A c)$ outside the hotel $(A c)$ 53.as $(\mathrm{Aj})$ he(S) was $(\mathrm{F})$ about to leave?(P) 54.Just $(\mathrm{Am})$ to make(F/P) sure(Ca)//55.no alibis(S) are $(\mathrm{F})$ invented...(P)56.Good(At), isn't(Fn) it(S), //57.to $\mathrm{know}(\mathrm{P}) / /$ 58.that( $(\mathrm{Aj})$ some organs of government(S) still(Am) perform(F/P) effectively(Ac) in this country(Ac)".

59."Can (Fml) I(S) speak(P) with him?(Ac)"

60."How $(\mathrm{Wh} / \mathrm{Ac})$ do(F) you(S) mean $(\mathbf{P})$ ? 61. Have (Fn) you(S) not been speaking $(\mathrm{P})$ with him?(Ac) 62.Oh(At), I(S) think(F/P)// 63.I(S) see(F/P) what(Wh/C) you(S) mean(F/P). 64.He(S) isn't(Fn) in custody or anything of the sort(Ac). 65.Not yet(mn). 66.So(At) I(S) certainly (Am)think (F/P)// 67.you(S) should(Fml) see $(P)$ him $(C)$. 68.But first of all $(A j) \quad I(S) \operatorname{want}(F)$ him(C) suspended(P) from duty $(A c) / /$ 69.and $(A j)$ barred(P) completely $(A c)$ from the premises of the Gazette(Ac).70.Is (F) that (S) clear?(Ca)"

71." $\mathrm{No}(\mathrm{At})$ it(S) is $\operatorname{not}(\mathrm{Fn})$. 72.I(S) am(F) sorry(Ca) Your Excellency(Av) 73.but(Aj) I(S) will not(Fnms) write(P) 
a letter $(C) / /$ suspending $(P)$ the Editor of the National Gazette(C) 74. simply because $(A j)$ some zealous security officer(S) has(F) come up $(P)$ with a story....(Ac)

75.' 'I(S) see(F/P)//76. I(S) have $(F)$ been wasting $(P)$ my breath....(C)

77."'If(Aj) they(S) think $(F / P) / / 78$. they(S) have $(F / P)$ a case $(C)$ against him $(A c)$ 79.let them(S) send(F/P) $\operatorname{him}(C)$ a query $(C)$ themselves $/ / 80$.or $(\mathrm{Aj})$ suspend $(\mathrm{P})$ him(C) 81.if $(\mathrm{Aj})$ they $(\mathrm{S})$ have(F/P) no patience $(\mathrm{C})$ for such bureaucratic niceties as queries(Ac). 82.I(S) don't(Fn) see (P)// 83.how(Wh/C) I (S) come (F/P) into it (Ac)."

84."'Listen $(F / P)$. 85. The way $(A c) I(S)$ see $(F / P)$ it $(C) / /$ 86.this matter $(S)$ is not $(F n)$ likely $(A o) / / 87$.to end $(P)$ with mere suspension $(A c) / /$ 88.for conspiring $(P)$ with thugs $(A c) / /$ 89.to invade $(P)$ the Presidential Palace $(C)$. 90.That $(\mathbf{S})$ may $(\mathrm{Fms})$ be $(\mathrm{P})$ only the merest tip of the iceberg(C). 91.There(S) is $(\mathrm{F})$ some indication(C) //92.that(Aj) Ikem (S) might $(\mathrm{Fms})$ have colluded $(\mathrm{P})$ with these same people(Ac)// 93.to sabotage $(\mathrm{P})$ the presidency referendum $(C)$ two years ago(Ac). 94.I(S) don't $(F n)$ mind telling $(P)$ you(C)// 95.that $(A j)$ your own role in that fiasco(S) was $(F)$ never $(A m)$ cleared up(P) satisfactorily either $(A c) / / 96$.and $(A j)$ may $(F m s)$ well $(A t)$ come up $(\mathrm{P})$ for further investigation.(Ac)"

97. "What (Wh/C) on earth $(A C)$ are(F) you(S) talking(P) about...? (Ac)"

98."So(At) I(S) sincerely (Ao) hope-(F/P)99.and(Aj) pray-(P) 100.that(Aj) you (S) will not(Fml) make (P) your own position (C).... 101. You know (At) ... more difficult (Ac) at this stage (Ac). 102.It (S) would(Fms) be (P) most unwise $(\mathrm{Ca}) / /$ 103.I(S) can $(\mathrm{Fms})$ assure $(\mathrm{P})$ you(C). 104.If(Aj) I(S) were $(\mathrm{F})$ in your shoes $(\mathrm{Ac}) / /$ 105.I(S) would(Fms) go(P) and $(A j)$ issue $(P)$ the letter(C) as(Aj) instructed(P)//106. And $(A j)$ await(P) further developments.(C)"

107."And $(\mathrm{Aj})$ if(Aj) I(S) refuse?(F/P) "

108'I(S) shouldn't (Fnml)//109. if $(\mathrm{Aj}) \mathbf{l}(\mathrm{S})$ were $(\mathrm{F})$ you. $(\mathrm{C})$ "

110. "Well (At), Your Excellency $(A v)$, for once $(A C) I(S)$ am $(F)$ turning $(P)$ you(C) down $(P)$. 111. I(S) will not (Fnms) carry out $(P)$ this instruction $(\mathrm{C}) / /$ 112.and $(\mathrm{Aj}) \mathrm{I}(\mathbf{A})$ hereby $(\mathbf{C l})$ tender $(\mathbf{P m} 36)$ my resignation. $(\mathbf{G})$ "

113"Resignation! Ha ha ha ha ha. (mn) 114.where(Wh/Ac) do(F) you(S) think (P)//115.you(S) Are (F)?

116. Westminster or Washington $D C$ ? $(\mathrm{mn})$ 117. Come on $(\mathrm{F} / \mathrm{P})$ ! 118. This $(\mathrm{S})$ is $(\mathrm{F})$ a military government $(\mathrm{C})$ in a backward West African State(Ac) 119.called(P) Kangan...(C)

120." We(S) wouldn't(Fnms) be(P) so backward(Ca) 121.if(Aj) we(S) weren't(Fn) so bent on remaining $(P)$ so ...(Ac)"

122."Some $\operatorname{day}(\mathrm{Ac})$ you(S) will $(\mathrm{Fms})$ have $(\mathrm{P})$ a chance $(\mathrm{C}) / /$ 123.to change(P) all that $(\mathrm{C}) / /$ 124.when $(\mathrm{Wh} / \mathrm{Ac})$ you(S) become $(F / P)$ the boss $(C)$. 125.Right now $(A c)$ this boss(S) here(Ac)won't(Fnms) accept $(P)$ resignations $(C)$ 126.unless $(\mathrm{Aj})$ of course $\mathrm{he}(\mathrm{S})$ has $(\mathrm{F})$ taken $(\mathrm{P})$ the trouble $(\mathrm{C})$ himself $/ / 127$.to ask $(\mathrm{P})$ for them $(\mathrm{Ac})$. 128.Right? $(\mathrm{mn})$ 129.This $(\mathrm{S})$ may $(\mathrm{Fms})$ be $(\mathrm{P})$ strange $(\mathrm{Ca})$ to you(Ac)//130.I(S) know(F/P)131.because $(A j)$ up until( $(\mathrm{Aj})$ now $(\mathrm{Ac})$ this same boss $(\mathrm{S})$ has $(\mathrm{F})$ allowed(P) //132.you and others(S) to call(F/P) the shots $(\mathrm{C})$. 133. Not any more, Chris $(\mathrm{mn})$. 134.I (S)will(Fms) be $(\mathrm{P})$ doing $(\mathrm{P})$ the calling $(\mathrm{C})$ from now on $(\mathrm{AC}) / /$ 135.and(Aj) $\mathbf{I}(\mathbf{S})$ intend(F) to call $(\mathrm{P})$ quite a few $(\mathrm{C})$ before $(\mathrm{Aj})$ 136.I(S) am(F) done $(\mathrm{Ca})$. 137.Now(Ac) is(F) that(S) clear(Ca)?// 138.I(S) want(F/P) that letter $(C) / / 139$.to be(P) in lkem's hands(Ac) by close of work today (Ac), without fail(Ac). 140.You (S) may(Fml) go (P) now (Ac).

141.Chris(S) left(F/P) without another word(Ac) //142.but(Aj) unshaken(Ca) in his defiance(Ac). 143.He(S) made for $(F / P)$ his office $(A c), / / 144$.intending to begin( $P$ ) right away $(A c)$ the removal of his private papers and $\operatorname{odds}(C) / / 145$.and $(A j)$ ends $(P)$ to his residence $(A c)$ 146.until( $(\mathrm{Aj})$ he(S) could(Fms) vacate( $P$ ) there $(A c)$ as well(Aj). 147.As soon as $(A j)$ he $(S)$ stepped into $(F / P)$ his office $(C)$, 148.however(Aj), he(S) was(F) handed(P) the telephone $(C)$ by a flustered secretary $(A c) .149$. His Excellency on the line.(mn)

150. "Yes, Chris $(m n)$. 151. I(S) have $(F)$ reconsidered $(P)$ this matter $(C)$. 152.You $(S)$ do $(F)$ have $(P)$ a point (C) 153.in not wishing to write $(P m l)$ the suspension letter $(C)$ yourself(Ac). 154. I(S) wanted $(F)$ to do $(P)$ you $(C)$ the honour $(C)$ 155.of appearing $(F)$ to be(P) still $(A c)$ in charge of your ministry $(C)$. 156.But(Aj) never (Am) mind (F/P). 157.We (S) will(Fms) take $(P)$ it $(C)$ from here (Ac). 158.Mean-while the SRC Director (S) will $(F m l)$ be chatting $(P)$ with you $(A c)$ on a number of leads $(A c)$ 159.He(S) has $(F)$ developed $(P)$ on the bungling of the referendum and other matters $(A c)$. 160.For God's sake(mn)give(F/P) him(C) maximum cooperation.(C)"

\section{EXCERPT N²: From Purple Hibiscus by Chimamanda Ngozi Adichie, (Pp 178-180)}

1.Amaka(S) picked up(F/P) the plaintains(C) 2. And(Aj) pressed(P) each(C) between her fingers(Ac),3. As if(Aj) she(S) would( $F m l)$ figure out $(P)$ 4.why $(A j)$ they $(S) \operatorname{cost}(F / P)$ so much $(A c) 5$. By(Aj) doing $(P)$ that $(c)$. 6.She (S) took (F/P) them (C) inside (Ac) 7. Just $(\mathrm{Am})$ as $(\mathrm{Aj})$ Father Amadi (S) drove in (F/P)8. And (Aj) parked $(P)$ in front of the flat $(A c)$. 9. His windscreen $(S)$ caught $(F / P)$ the sun $(C)$ 10.and $(A j)$ glittered $(P)$. 11.He (S) bounded up $(F / P)$ the few stairs $(C)$ to the verandah $(A c)$, holding $(P)$ his soutane $(C)$ up like a bride holding a wedding dress(Ac).12. He (S) greeted (F/P) papa-Nnukwu (C) first(Aj), 13.before(Aj) hugging (P) Aunty Ifeoma (C)14. And $(A j)$ shaking $(P)$ hands $(C)$ with the boys $(A C)$. 15.I(S) extended (F/P) my hand (C) 16.so that $(A j)$ we (S) could(Fms) shake $(P)$, 17.my lower lip(s) starting(F) to tremble(P).

18. "Kambili(Av)," he(S) said(F/P), 19.holding(P) my hand(C) a little longer than the boys'(Ac). 
20."Are(F) you (S) going (P) somewhere (Ac), Father?(Av)"21. Amaka(S) asked (F/P),22. Coming (P) onto the verandah $(A c)$.23. "You (S) must $(F \mathrm{ml})$ be baking $(P)$ in that soutane $(A c)$."

24."I(S) am $(F)$ going over $(P)$ 25.to give $(P)$ some things $(C)$ to a friend of mine, [[ the priest who(S) came back(F/P) from Papua New Guinea(Ac)]](C). 26. He (S) returns (F/P) next week (Ac)."

27."Papua New Guinea (mn). 28.How(Ac) did(F) he (S) say (P)//the place (S) is (F), eh?" (At)29. Amaka (S) asked $(F / P)$.

30."He $(S)$ was $(F)$ telling $(P)$ a story $(C)$ of crossing a river $(A c)$ by canoe $(A c)$, with crocodiles right underneath $(A c)$. 31. He (S) said $(F / P) 32$. he $(S)$ is not $(F n)$ sure $(\mathrm{Ca})$ 33.which $(W h / S)$ happened $(F / P)$ first, $(A j)$ 34.hearing $(P)$ the teeth of the crocodiles snapping $(C) 35$. Or $(A j)$ discovering $(P) 36$. that $(A j)$ he $(S)$ had(F) wet $(P)$ his trousers (C)."

37."They (S) had better not $(\mathrm{Fnml})$ send $(P)$ you $(C)$ to a place $(A c)$ like that $(A c), " 38$. Aunty Ifeoma(S) $\operatorname{said}(F / P)$ with a laugh $(A c), 39$. Still $(A j)$ fanning $(P)$ herself $(C) 40$.and $(A j)$ sipping $(P)$ from a glass of water $(A c)$.

41."I(S) don't $(F n)$ even $(A j)$ want $(P)$ 42.to think $(P)$ about your leaving $(A C)$,

Father $(A v), 43$. "Amaka (S) said $(F / P)$.44."You $(S)$ still $(A j)$ don't $(F)$ have $(P)$ an idea $(C)$ where $(W h / A c)$ and $(\mathrm{Aj})$ when $(\mathrm{Wh} / \mathrm{Ac})$, okwia?(At)

45."No(Ap). 46.Sometime next year, perhaps(Am) (mn)."

47."Who (Wh/S) is(F)sending (P) you (C)?" 48.Papa-Nnukwu (S) asked (F/P), in his sudden way (Ac) 49.that $(\mathrm{Aj})$ made $(\mathrm{F})$ me $(\mathrm{C})$ realize $(\mathrm{P}) 50$. he $(\mathrm{S})$ had $(\mathrm{F})$ been following $(\mathrm{P})$ every word spoken in lgbo $(C)$.

51. "Father Amadi (S) belongs (F/P) to group of priests ndi missionary $(A c), 52$. And $(A j)$ they(S) go( $F / P)$ to different countries(Ac)53.to convert(P) people(C),"54.Amaka(S) said(F/P). 55. She (S) hardly(Am) peppered $(F / P)$ her speech $(C)$ with English words $(A c) 56$.when(Aj) she (S) spoke (F/P) to Papa-Nnukwu (Ac), 57.as $(A j)$ the rest of us (S) inadvertently(Ac) did (F/P).

58."Ezi okwu? (Ao)" Papa-Nnukwu (S) looked up (F/P), his milky eye on Father Amadi (Ac). 59."Is (F) that (S) so $(A c)$ ? 60.Our own sons (S) now(Aj) go (F/P) 61.to be $(P)$ missionaries $(C)$ in the white man's land? $(A c)$ "

62."We (S) go (F/P) to the white man's land and the black man's land (Ac), sir," (Av) 63.Father Amadi (S) said $(\mathrm{F} / \mathrm{P}) .64$. "Any place $(\mathrm{Ac})$ that $(\mathrm{S})$ needs $(\mathrm{F} / \mathrm{P})$ a priest $(\mathrm{C})$ "

65."It (S) is (F) good (Ca), my son(Av). 66.But(Aj) you (S) must(Fml) never(Am) lie (P) to them (Ac).67. Never(Am) teach (F/P) them (C) 68.to disregard (P) their fathers (C)" 69.Papa Nnukwu (S) looked away $(F / P)$, 70.shaking $(P)$ his head $(C)$.

71."Did(F) you(S) hear(P) that (C), Father?"(Av) 72.Amaka (S) asked (F/P). 73. "Don't (Fn) lie (P) to those poor ignorant souls (Ac)."

74."It (S) will(Fms) be (P) hard (Ca) not to, 75.but(Aj) I (S) will (Fml)try (P)," 76.Father Amadi (S) said (F/P), in English (Ac). 77. His eyes (S) crinkled (F/P) at the corners (Ac) 78.when (Aj) he (S) smiled (F/P).

79. "You(S) know (F/P), Father (Av), 80.it(S)'s (F) like making (P) okpa (Ac)," 81.Obiora (S) said (F/P).82. "You (S) mix (F/P) the cowpea flour and palm oil (C), 83.then(Aj) you (S) steam-cook (F/P) for hours(AC). 84. You(S) think (F/P)85. you (S) can(Fml) ever(Am) get (P) just(Am) the cowpea flour (C)? Or(Aj) just(Am) the palm oil?(C)"

86. "What (WH) are (F) you (S) talking (P) about? (Ac)" 87.Father Amadi (S) asked (F/P).

88. "Religion and oppression," (mn) 89. Obiora (S) said (F/P).

90. "You(S) know (F/P) 91. There $(S)$ is $(F)$ a saying $(C)$ 92.that $(A j)$ it $(S)$ is not(Fn) just $(A m)$ the naked men $(C)$ in the market $(A C)$ 93.who (S) are (F) mad? (Ca)" 94.Father Amadi (S) asked (F/P). 95. "That streak of madness $(S)$ has $(F)$ returned $(P)$ 96. And $(A j)$ is $(F)$ disturbing $(P)$ you $(C)$ again $(A j)$, okwia?" (At)

97. Obiora (S) laughed (F/P), 98.and (Aj) so (Aj) did (F) Amaka (S), in that loud way (Ac) 99. It (S) seemed $(\mathrm{F} / \mathrm{P})$ 100. Only (Aj) Father Amadi (S) could (Fml) get out $(\mathrm{P})$ of her $(\mathrm{Ac})$.

101"Spoken(P) like the true missionary priest, Father(Av)," (Ac) 102.Amaka (S) said (F/P).103. "When (Aj) people (S) challenge (F/P) you $(C)$, 104. label $(P)$ them $(G)$ mad $(\mathrm{Ca})$.

105. "See (P) how (Ac) 106.your cousin (S) sits (F/P) quiet (Ca) 107.and (Aj) watches? (P)"108. Father Amadi(S) asked (F/P), 109.gesturing $(P)$ to me $(A c)$.110. "She $(S)$ does not $(F n)$ waste $(P)$ her energy $(C)$ 111.in picking $(P)$ never-ending arguments $(C) .112$. But $(A j)$ there $(S)$ is $(F)$ a lot going on $(C)$ in her mind $(A C)$, 113.I (S) can (Fml) tell (P)." 